
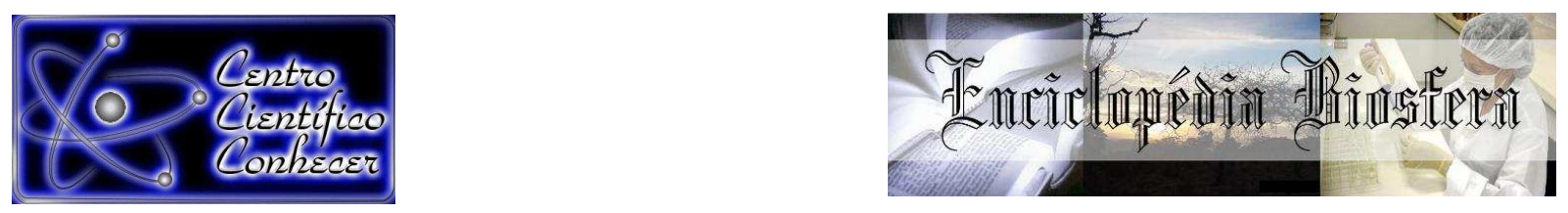

\title{
DOSES DE POTÁSSIO NO TRIGO CULTIVADO EM SUCESSÃO AO MILHO SILAGEM
}

Alieze Nascimento da Silva ${ }^{1}$, Claudir José Basso ${ }^{2}$, Dionei Schmidt Muraro ${ }^{3}$, Diego Alan Breitenbach ${ }^{4}$

1 Mestranda no Departamento de Ciências Agronômicas e Ambientais da Universidade Federal de Santa Maria Campus de Frederico Westphalen, RS, Brasil, alieze.agro@rocketmail.com.

2 Professor do Departamento de Ciências Agronômicas e Ambientais da Universidade Federal de Santa Maria, Campus de Frederico Westphalen, RS, Brasil

3 Graduando em Agronomia, Departamento de Ciências Agronômicas e Ambientais da Universidade Federal de Santa Maria, Campus de Frederico Westphalen, RS, Brasil

4 Graduando em Agronomia, Departamento de Ciências Agronômicas e Ambientais da Universidade Federal de Santa Maria, Campus de Frederico Westphalen, RS, Brasil

Recebido em: 08/04/2016 - Aprovado em: 30/05/2016 - Publicado em: 20/06/2016 DOI: 10.18677/Enciclopedia_Biosfera_2016_045

\section{RESUMO}

A disponibilidade de macronutrientes no solo é um dos fatores que mais impacta na produção sendo necessário o suprimento adequado para que as culturas possam expressar seu potencial de rendimento. Objetivou-se avaliar doses de potássio em cobertura no trigo em sucessão ao milho silagem no Noroeste do Rio Grande do Sul. O trabalho foi conduzido no Município de Ajuricaba (RS), no ano de 2013. A área onde foi conduzido o experimento foi cultivada anteriormente com safra e safrinha de milho para produção de silagem. O delineamento experimental foi de blocos ao acaso com quatros repetições, parcelas de $3 \times 3 \mathrm{~m}$ e constituído por cinco tratamentos que correspondem as doses de potássio $\left(0 ; 40 ; 80 ; 120\right.$ e $160 \mathrm{Kg} \mathrm{K}_{2} \mathrm{O}$ ha $\left.^{-1}\right)$. A cultivar utilizada foi TBIO Itaipu com aproximadamente 350 plantas por metro quadrado. Avaliaram-se: massa seca da parte aérea, altura de planta, o número de grãos por espiga, produtividade de grãos, peso hctolítrico e teor de proteína. A melhor resposta do trigo à adubação potássica ocorreu com aplicação de $80 \mathrm{~kg} \mathrm{~K}_{2} \mathrm{O} \mathrm{ha}{ }^{-1}$, com maior produção de massa seca e produtividade de grãos. A altura de plantas do trigo respondeu de forma linear à aplicação de doses de potássio e as doses de potássio não influenciaram as variáveis pH, proteína e número de grãos por espiga.

PALAVRAS- CHAVE: Adubação potássica, forragem, sucessão de culturas. 


\title{
POTASSIUM DOSES IN WHEAT GROWN CORN SUCCESSION TO SILAGE
}

\begin{abstract}
Soil fertility is one of the factors that impact production requiring an adequate supply of nutrients to cultures to express their yield potential. This study aimed to evaluate doses of potassium coverage in wheat in succession to corn silage in the Northwest Region of Rio Grande do Sul. The work was conducted in the municipality of Ajuricaba (RS), in 2013. The area where it was conducted the experiment was previously cultivated with crop and second crop corn for silage. The experimental design was a randomized block design with four replications, plots of $3 \times 3 \mathrm{~m}$ and consists of five treatments that correspond to the potassium doses $\left(0,40,80,120\right.$ and $160 \mathrm{Kg} \mathrm{K}_{2} \mathrm{O}$ ha $\left.{ }^{-1}\right)$. The cultivar used was TBIO Itaipu with approximately 350 plants per square meter. Evaluated: shoot dry weight, plant height, number of grains per spike, grain yield, hectolítrico $(\mathrm{pH})$ weight and protein content. The best wheat response to potassium fertilization occurred with application of $80 \mathrm{~kg} \mathrm{~K}_{2} \mathrm{O} \mathrm{ha}^{-1}$, with a higher dry matter production and grain yield. Wheat plant height responded linearly to the application of doses of potassium and potassium doses did not influence variables $\mathrm{pH}$, protein and number of grains per spike.
\end{abstract}

KEYWORDS: Potassium fertilization, crop succession, silage.

\section{INTRODUÇÃO}

A crescente demanda por cereais e a limitação de áreas agrícolas tem intensificado de forma expressiva os cultivos agrícolas, necessitando práticas de manejo que potencializem a eficiência na utilização dos recursos naturais e insumos agrícolas, principalmente fertilizantes, para que haja economia de insumos, aumento da produtividade e maior eficiência econômica (DORÉ et al., 2011; HOCHMAN et al., 2013).

No Brasil, a silagem de milho é a forrageira mais consumida pelos animais para produção de leite, promovendo melhor resposta no ganho de peso e na produção de leite quando fornecido a bovinos (CONAB, 2014), principalmente na região Sul, onde as variações climáticas ocasionam estacionalidade na produção de forrageiras durante o inverno. As gramíneas em geral, como a cultura do milho e trigo demandam elevada quantidade de potássio (FOLONI et al., 2009). O potássio (K) é um macronutriente que possui papel fundamental para a nutrição das plantas, por ser o cátion mais abundante no tecido vegetal, sendo um nutriente com relevantes funções fisiológicas e metabólicas, translocação de assimilados e, também absorção de nitrogênio e síntese proteica, tornando-se, portanto, limitante em sistema de utilização intensiva de solo. (SIMILI et al., 2008; KAUTZ et al., 2013).

A disponibilidade e a absorção de $\mathrm{K}$, assim como a capacidade de suprimento, depende das interações dinâmicas entre o solo e disponibilidade de $\mathrm{K}$, assim a aplicação de fertilizantes e a CTC do solo, além da ciclagem do nutriente pelas plantas, manejo agronômico e propriedades do solo refletem diretamente (ASSENG et al., 2012; SCANLAN et al., 2015).

$\mathrm{Na}$ cultura do milho objetivando a produtividade de grãos, o $\mathrm{K}$ em sua maior parte retorna ao solo após a colheita e a senescência da palha do milho no solo, devido a sua grande mobilidade no solo e por não possuir grandes funções estruturais na 
planta, o retorno ao solo deste elemento é muito rápido (PAVINATO et al., 2008; LIU et al., 2012). Porém, a dinâmica do potássio muda no cultivo do milho destinado á produção de silagem, devido à retirada de toda planta do campo interrompendo a ciclagem de grande parte do $\mathrm{K}$ no solo, exigindo maior cuidado na recomendação do nutriente para os próximos cultivos (YAMADA \& ROBRTS, 2005; MU et al., 2012).

Estudando a dinâmica do $\mathrm{K}$ no solo em áreas destinadas a produção de milho silagem, UENO et al., (2011) obtiveram uma exportação média de $76 \mathrm{~kg} \mathrm{ha}^{-1}$ a mais de $\mathrm{K}$ em relação ao exportado pelo milho destinado para produção de grãos. XIE et al. 2014 estudando por três ano o efeito da palha do milho e a aplicação de potássio no solo, observaram que a palha de milho combinada com a adubação potássica aumenta a produtividade das culturas subsequentes, mantém o equilíbrio e armazenamento de potássio no solo.

Dessa forma, o milho silagem inserido na sucessão de culturas é considerada uma cultura com alta extração e exportação de nutrientes, isso por que, toda a parte aérea da planta é retirada da lavoura (YANG et al., 2013). Por isso, pode haver rápido esgotamento de alguns nutrientes do solo, e de forma mais expressiva o potássio (SUN et al. 2012). Logo, no comparativo com cultivos de milho para produção de grãos comercial, problemas de fertilidade do solo se manifestarão mais cedo em áreas para produção de silagem principalmente quando se utiliza cultivos consecutivos de milho para essa finalidade principalmente em cultivo do milho safra e safrinha, prática essa muito utilizada por alguns produtores que possuem limitação de área para produção de silagem. Com isso a deficiência de potássio tem-se tornado frequente em áreas de cultivo de milho silagem (BAl et al., 2015).

O cultivo milho-trigo sem que haja adequada reposição do potássio, tem acarretado em deficiência deste elemento, mesmo nos solos férteis uma vez que a quantidade de potássio extraída em lavouras de milho pode ultrapassar $160 \mathrm{~kg} \mathrm{ha}^{-1}$ (COELHO, 2005). As plantas de trigo demandam elevada quantidade de macronutrientes, principalmente, nitrogênio e potássio (FOLONI et al., 2009). Este fato tem contribuído para a queda do rendimento, maior incidência de doenças e aparente redução na qualidade final do trigo. Para alguns autores, isso se deve ao fato das exportações de nutrientes serem maiores que as adições no sistema o que tem levado a insustentabilidade do sistema (ALAM et al., 2013).

Por isso, a hipótese que fundamenta esse trabalho é que mesmo em solos com teores de potássio acima do suficiente, ou considerados altos há uma resposta positiva na cultura do trigo cultivado em sucessão do milho silagem. Por isso Objetivou-se com a realização deste trabalho, avaliar doses crescentes de potássio na cultura do trigo em sucessão ao milho silagem na Região Noroeste do Rio Grande do Sul.

\section{MATERIAL E MÉTODOS}

Este trabalho foi conduzido no ano de 2012/2013 em área experimental no município de Ajuricaba, RS, Brasil, Região Noroeste do Rio Grande do Sul, cujas coordenadas são latitude 28 ' $^{\prime} 0.23^{\prime \prime S}$, longitude 53 '38'56.38"O, e uma altitude 403 metros. De acordo com a classificação climática de Köeppen, o clima da região se enquadra na descrição de Cfa (subtropical úmido), com ocorrência de verões quentes e sem ocorrência de estiagens prolongadas. A precipitação pluvial diária, ocorrida de julho de 2013 a novembro de 2013, está apresentada na Figura 1. 
O solo é classificado como Latossolo Vermelho distroférrico típico (EMBRAPA, 2013). Por ocasião da implantação do experimento, a área foi amostrada na camada de $0-10 \mathrm{~cm}$ e realizada a análise química do solo, apresentando as seguintes características expressas na Tabela 1.

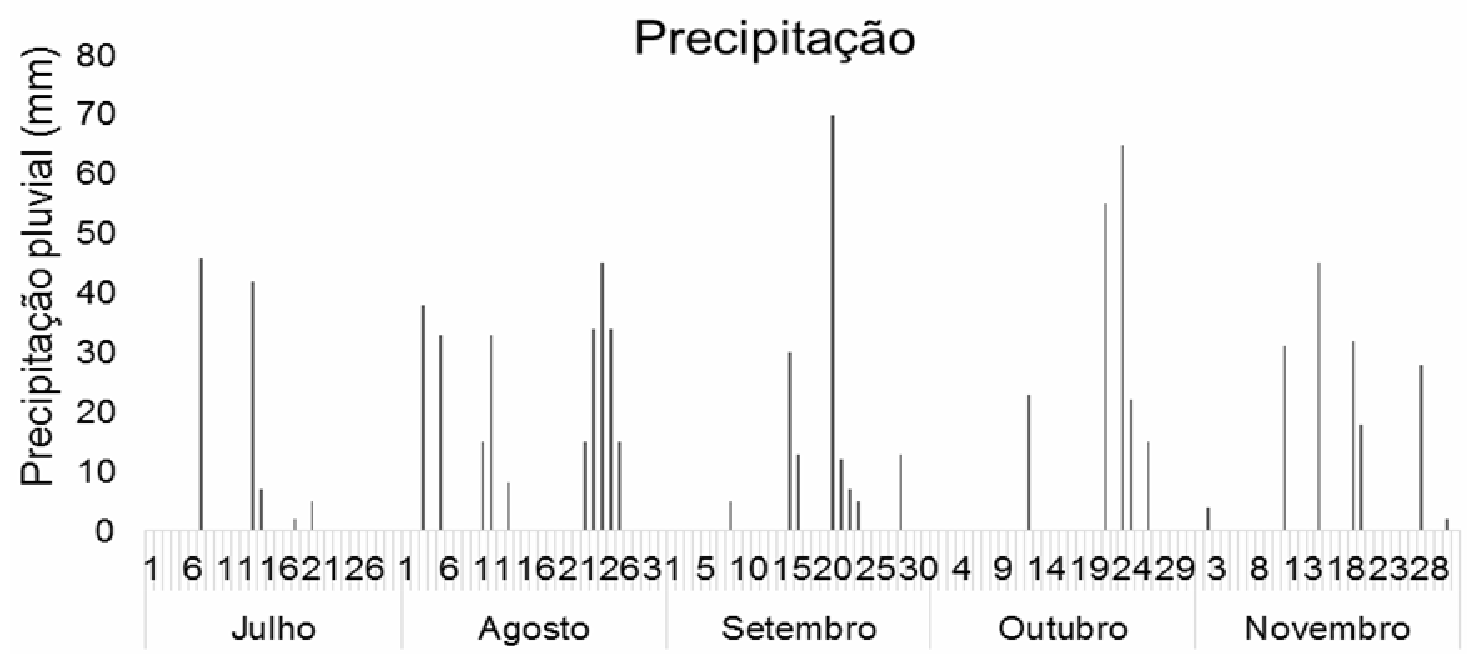

FIGURA 1 Precipitação durante a condução do experimento

A área onde foi conduzido o experimento foi cultiva anteriormente com safra e safrinha de milho para produção de silagem. O delineamento experimental utilizado foi de blocos ao acaso com quatros repetições e parcelas de $3 \times 3 \mathrm{~m}$. O experimento foi constituído por cinco tratamentos que corresponderam as doses de potássio $(0 ; 40 ; 80$; 120 e $160 \mathrm{Kg} \mathrm{K}_{2} \mathrm{O} \mathrm{ha}^{-1}$ ).

TABELA 1 Caracterização química do solo na profundidade de 0-10 cm

\begin{tabular}{|c|c|c|c|c|c|c|c|c|c|c|}
\hline $\begin{array}{l}\mathrm{Ph} \\
\mathrm{H}_{2} \mathrm{O}\end{array}$ & $P$ & $\mathrm{~K}$ & $\mathrm{Ca}$ & $\mathrm{Mg}$ & $\mathrm{H}+\mathrm{Al}$ & $\mathrm{Al}$ & CTC & $\begin{array}{c}\text { SAT. } \\
\text { BASES }\end{array}$ & Argila & M.0 \\
\hline & $--m$ & $7^{-3}-$ & ----. & & $\mathrm{cmol}_{\mathrm{C}} \mathrm{d}$ & -3 & ----- & ---------- & \%--- & \\
\hline
\end{tabular}

A semeadura do trigo foi realizada de forma mecânica em 02 de julho de 2013, utilizando-se o espaçamento de $0,17 \mathrm{~m}$ nas entrelinhas e aproximadamente 350 plantas por metro quadrado totalizando uma população final aproximada de 3,5 milhões de plantas ha ${ }^{-1}$. A cultivar de trigo utilizado neste estudo foram a TBIO ITAIPU, de estatura média, grãos semiduros, moderadamente resistente à germinação na espiga, ciclo médio e moderadamente resistente ao acamamento. A colheita foi realizada de forma manual no dia 08 de novembro de 2013, totalizando o cultivo 129 dias. 
A adubação mineral fosfatada $\left(\mathrm{P}_{2} \mathrm{O}_{5}\right)$ foi realizada por ocasião da semeadura de forma mecânica com aplicação $90 \mathrm{~kg} \mathrm{ha}^{-1}$ de Super Fosfato Simples. Já a adubação nitrogenada foi realizada 15 dias após a semeadura com $100 \mathrm{Kg} \mathrm{ha}^{-1}$ de uréia $(\mathrm{N})$. A fonte de potássio utilizada foi o cloreto de potássio ( $58 \%$ de $K)$, aplicado a lanço no solo logo após a semeadura do trigo. Para o manejo de plantas daninhas, paras e doenças seguiu-se a recomendação do manual da cultura (EMBRAPA, 2014).

As variáveis analisadas foram: a) massa seca da parte aérea: amostragem realizada no pleno florescimento coletando-se uma área de $0.15 \mathrm{~m}^{2}$ e secam em estufa até peso constante.; b) altura de planta; determinada na época de maturação como sendo a distância $(\mathrm{cm})$ do nível do solo ao ápice da espiga, excluindo as aristas, em 10 plantas aleatórias na parcela; c) produtividade de grãos; realizado através da colheita manual das plantas da área útil proveniente das três linhas centrais de cada parcela $\left(1,82 \mathrm{~m}^{2}\right)$ e em seguida, trilhagem mecânica. $O$ peso de cada amostra foi corrigido a $13 \%$ de umidade e transformado em $\mathrm{kg} \mathrm{ha}^{-1}$; d) número de grãos por espiga; determinado na colheita, onde foram coletadas dez espigas aleatórias na área útil de cada parcela, acondicionaram-nas em sacos de papel, devidamente identificadas, levando-as ao laboratório para avaliação; e) peso hectolitrico (peso hectolitro); f) teor de proteína; determinados utilizando-se o analisador de grãos Infratec ${ }^{\mathrm{TM}} 1241$ da marca FOSS.

Os dados obtidos foram submetidos à análise de variância (ANOVA) (Teste $F$, $\mathrm{p}<0,05)$. As médias das variáveis foram comparadas mediante análise de regressão. Para a análise estatística dos dados foi utilizado o software estatístico ASSISTAT Versão 7.7 beta (2015).

\section{RESULTADOS E DISCUSSÃO}

Durante o período de desenvolvimento do trigo, a umidade do solo não foi fator limitante aos seus desenvolvimento e produtividade. Com relação às doses de potássio fazendo-se um resumo da análise de variância para as variáveis estudadas, as doses de potássio não influenciaram de forma significativa as variáveis peso hectolitrico, proteína, número de grãos por espiga. Houve respostas significativas $(P<0,05)$ para as variáveis: produtividade de grãos, massa seca e altura de planta.

Quanto à produtividade de grãos de trigo, houve uma reposta positiva com o aumentou no o suprimento de potássio, ajustando-se ao modelo quadrático (Figura 2). De acordo com a equação, a máxima eficiência agronômica para produtividade de grãos do trigo foi obtida com a dose de $80 \mathrm{~kg} \mathrm{ha}^{-1}$, onde se observou uma produtividade de $5415,3 \mathrm{~kg} \mathrm{ha}^{-1}$. Na ausência da aplicação de potássio $\left(0 \mathrm{~kg}^{-1}\right.$ de $\left.\mathrm{K}^{2} \mathrm{O}\right)$ a produtividade média obtida foi de $4903,7 \mathrm{~kg} \mathrm{ha}^{-1}$, sendo esta $12,5 \%$ inferior à dose máxima de $160 \mathrm{~kg} \mathrm{ha}^{-1}$ de $\mathrm{K}_{2} \mathrm{O}$.

Os resultados obtidos referentes à produtividade de grãos no presente trabalho vão de encontro aos resultados obtidos por BAHMANYAR et al., (2008), que ao compararem a influência de diferentes doses de potássio na produtividade de grão de trigo e nos componentes de produção, observaram que $60 \mathrm{~kg} \mathrm{~K}_{2} \mathrm{O}$ ha $^{-1}$ foi suficiente para a máxima produtividade de grãos, apresentando comportamento quadrático em resposta ao aumento das doses.

A deficiência de potássio pode prejudicar o bom funcionamento dos estômatos, podendo diminuir a assimilação de $\mathrm{CO}_{2}$ e a taxa fotossintética (CECÍLIO \& 
GRANGEIRO, 2004). Dessa forma, a baixa produtividade com as doses menores pode estar associada à quantidade restrita de potássio no solo (MALAVOLTA, 2006).

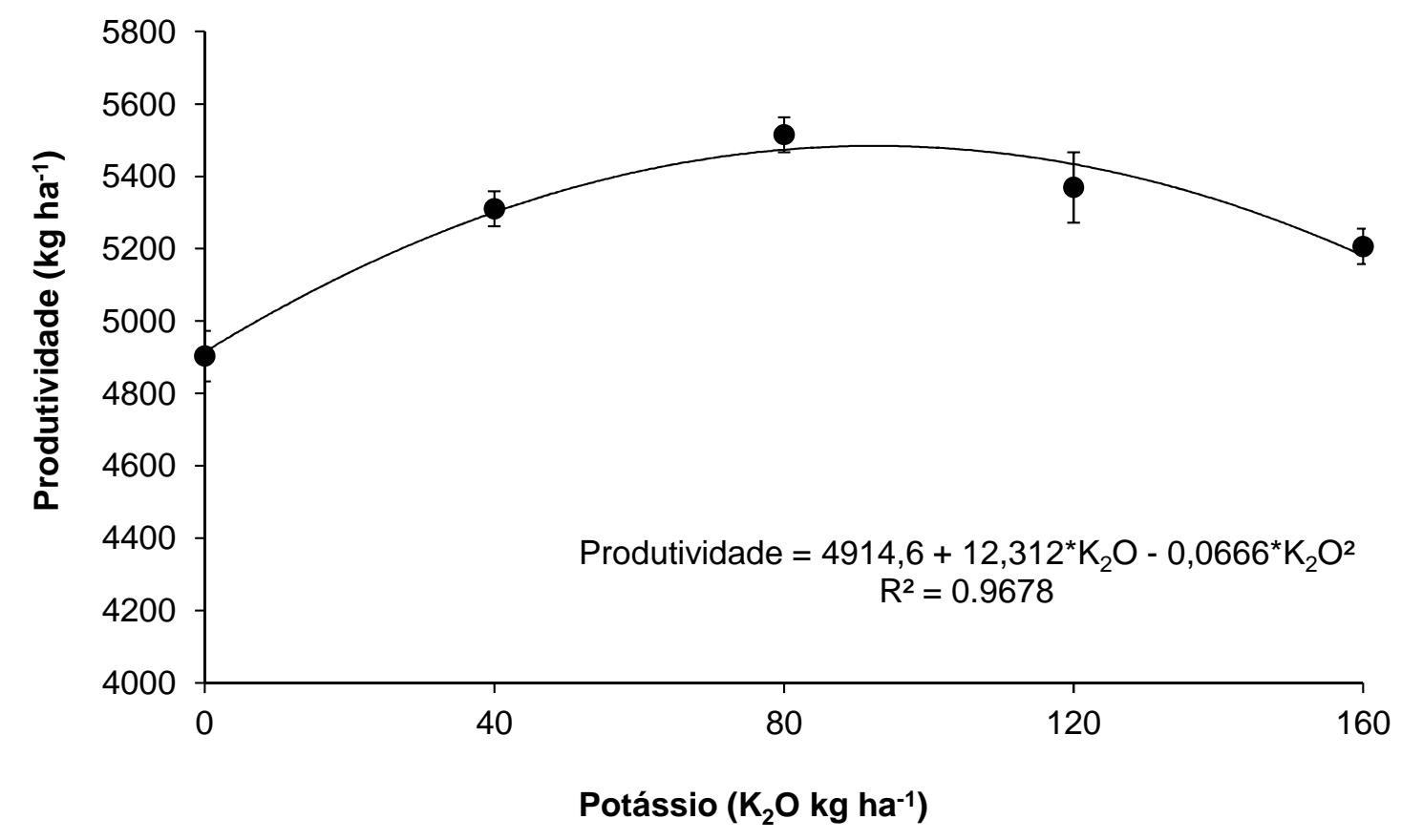

FIGURA 2 Produtividade de grãos de trigo, em função de doses de potássio

Por outro lado, segundo o mesmo autor, quando se aumenta da disponibilidade de potássio no meio além das necessidades nutricionais da cultura, como para estas altas dosagens de potássio, podem ocorrer inibição na absorção de cálcio e magnésio, chegando à maioria das vezes a ocasionar deficiência de ambos nutrientes. CARMONA et al. (2009), observaram em experimento com adubação potássica, que o excesso de potássio pode interferir negativamente na absorção de outros cátions pelas culturas, pela competição dos sítios de absorção. Dessa forma, os teores de potássio no solo não devem ser considerados, por si só, para a recomendação de fertilizantes, devendo ser observado também os teores de cálcio e magnésio.

A produção de massa seca da parte aérea do trigo apresentou reposta significativa às doses de potássio, obedecendo ao modelo quadrático de regressão (Figura 3). Na dose de $80 \mathrm{~kg} \mathrm{ha}^{-1}$ de potássio se observou a máxima eficiência agronômica para essa variável, sendo está de $11650,0 \mathrm{~kg} \mathrm{ha}^{-1}$. Já no tratamento com ausência de aplicação de potássio $\left(0 \mathrm{~kg} \mathrm{ha}^{-1} \mathrm{~K}_{2} \mathrm{O}\right)$, se observou a menor produção de massa seca $\left(9293,3 \mathrm{~kg} \mathrm{ha}^{-1}\right)$, com redução de $25,3 \%$ e relação ao melhor tratamento $\left(80 \mathrm{~kg} \mathrm{ha}^{-1} \mathrm{~K}_{2} \mathrm{O}\right)$. 


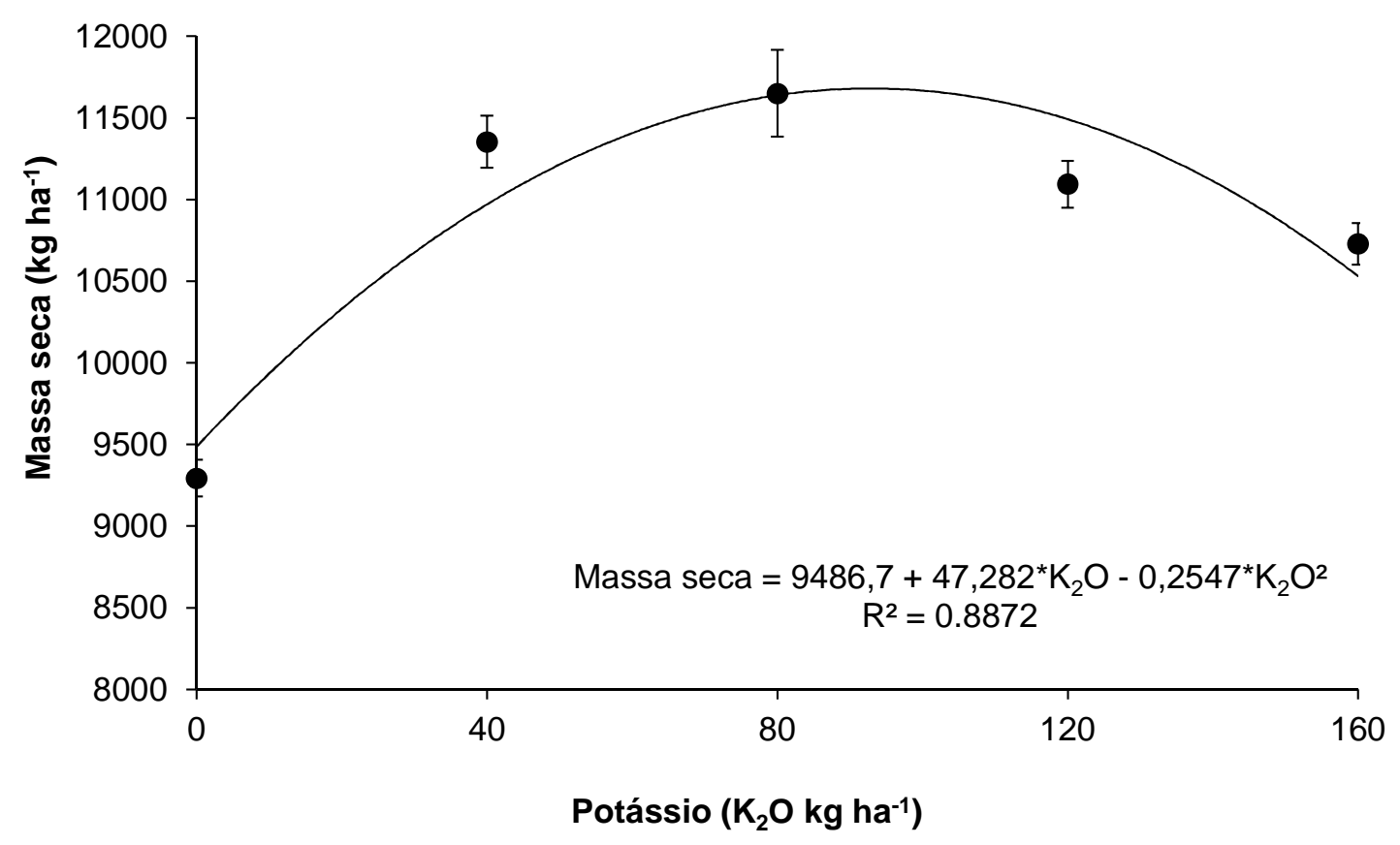

FIGURA 3 Massa seca da parte aérea de plantas de trigo, em função de doses de potássio.

Os resultados encontrados no presente trabalho são semelhantes aos observados por AKHTAR et al., (2002) onde a aplicação de $75 \mathrm{~kg} \mathrm{~K}_{2} \mathrm{O} \mathrm{ha}^{-1}$ aumentou a produção de massa seca em $10 \%$, porém o mesmo autor encontrou máxima eficiência agronômica com a dose de $150 \mathrm{~kg}$ de $\mathrm{K}_{2} \mathrm{O}$ ha $^{-1}$ onde o aumento foi de $35 \%$ em relação ao tratamento testemunha. VIANA et al., (2010) também verificaram que a dose de 80 $\mathrm{K}_{2} \mathrm{O} \mathrm{ha}^{-1}$ foi responsável pela máxima produção de massa seca da parte aérea do trigo. HECKMANN \& KAMPRATH (1992) observaram que, em solo com alto teor de fósforo e alto teor de potássio disponível, o acúmulo de matéria seca de milho foi incrementado com a aplicação de até $56 \mathrm{~kg} \mathrm{ha}^{-1}$ de $\mathrm{K}_{2} \mathrm{O}$. FAQUIM et al., (1995) também observaram efeito quadrático e incrementos significativos com doses de potássio para matéria seca da parte aérea para plantas forrageiras, onde no total dos cortes a produção aumentou em quatro vezes e cinco vezes para capim - braquiária e colonião, respectivamente.

A absorção do potássio pelas raízes se dá principalmente por difusão, e esta absorção está diretamente relacionada com o teor de umidade do solo, esta pode ser uma justificativa à alta produção de matéria seca do trigo, já que durante seu ciclo a quantidade e distribuição das chuvas foram muito favoráveis ao crescimento de plantas e talvez isso justifique a falta de resposta a doses maiores de potássio aplicadas (JIA et al., 2014). BRUNETTO et al., (2005) aplicaram anualmente na semeadura da cultura de verão doses de $\mathrm{KCl}$ variando de 0 a $200 \mathrm{~kg} \mathrm{ha}^{-1}$ de $\mathrm{K}_{2} \mathrm{O}$ a um solo com $110 \mathrm{~g} \mathrm{~kg}^{-1}$ de argila e cultivaram soja, milho, aveia, e aveia + ervilhaca. Eles verificaram que a produção acumulada de massa seca das plantas e de grãos aumentou com o aumento das doses de potássio, o teor de potássio no solo era considerado médio pelos autores.

Em relação à altura das plantas, essa obedeceu ao modelo linear de regressão (Figura 4). De acordo com o modelo de regressão, a altura da planta aumentou de 94,27 para 97,3 indicando que as plantas respondem positivamente a essa variável à 
medida que há maiores quantidades de potássio disponível no solo. Isso pode estar associado ao fato do potássio ser um elemento de grande importância para as gramíneas, sendo responsáveis por aumentar a resistência á doenças, conferindo maior vigor á planta, além de promover translocação de carboidratos e reduzir o acamamento. Além disso, segundo BAl et al. (2015), plantas bem supridas em potássio têm a concentração de potássio elevada nos tecidos e, consequente redução do potencial hídrico, o que leva a um maior acúmulo de água nos tecidos e a soma dessas funções pode ser a justificativa para o incremento linear da altura do trigo no presente trabalho.

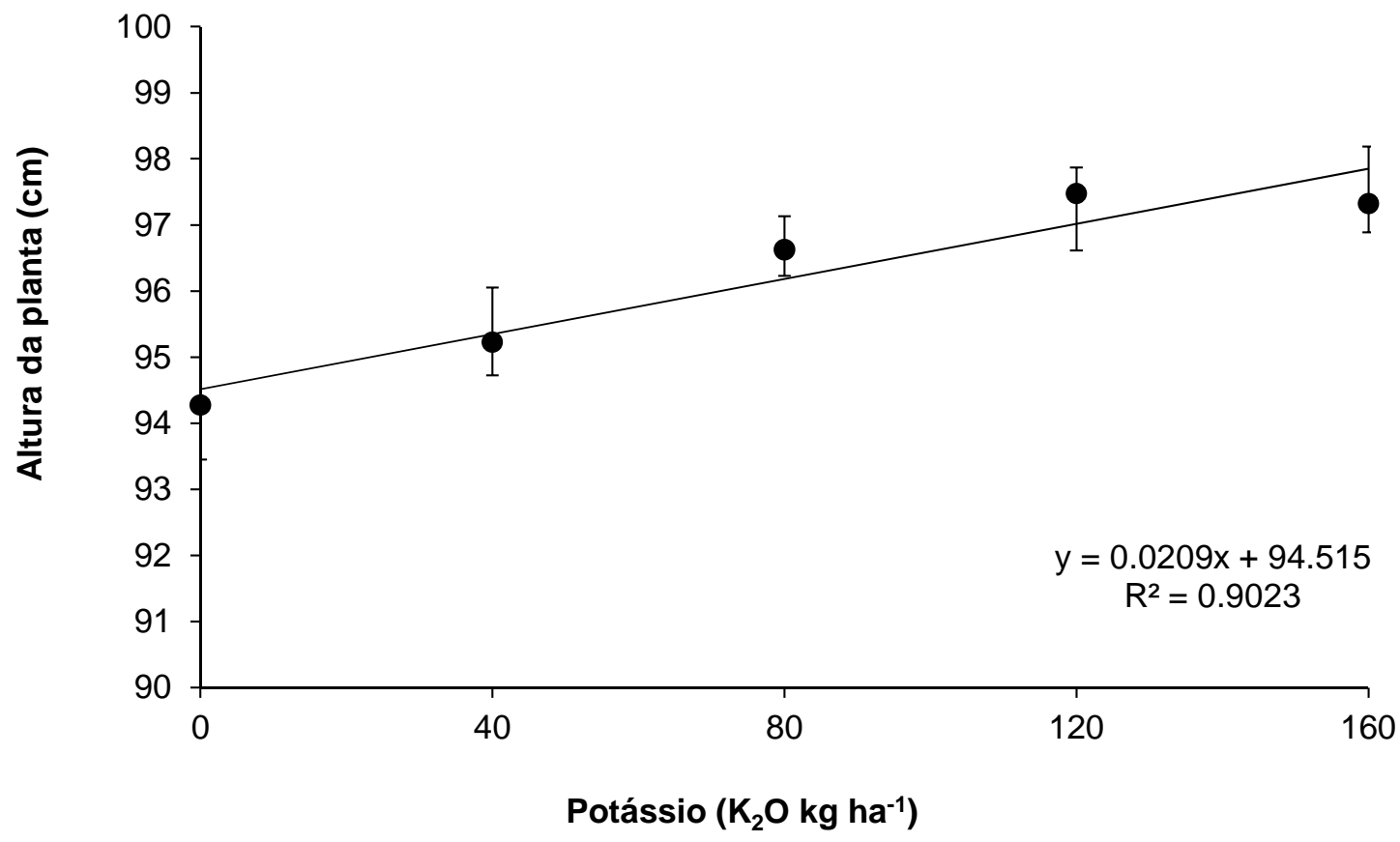

FIGURA 4 Altura de plantas de trigo, em função de doses de potássio.

Efeito também significativo foi observado por EL-TILIB et al., (2004) para a altura das plantas na soqueira de cana-de-açúcar, em função da aplicação de potássio durante o crescimento da cultura avaliadas (4 até 10 meses após o brotamento da soqueira), sendo a melhor resposta obtida com a dose de $86 \mathrm{~kg} \mathrm{ha}^{-1}$ de $\mathrm{K}_{2} \mathrm{O}$.

\section{CONCLUSÕES}

A melhor resposta do trigo à adubação potássica foi observada para a dose de $80 \mathrm{~kg} \mathrm{~K}_{2} \mathrm{O} \mathrm{ha}^{-1}$, promovendo maior produtividade de grãos e de massa seca de parte aérea no trigo.

Quanto a altura, a cultura responde de forma linear à aplicação de doses crescentes de potássio.

As doses de potássio nas condições estudadas não influenciaram as variáveis peso hectolitrico, proteína e número de grãos por espiga. 


\section{REFERÊNCIAS}

ALAM, M.M.; KARIM, M.R.; LADHA, L.K. Integrating best management practices for rice with farmers' crop management techniques: a potential option for minimizing rice yield gap. Field Crops Research, v. 144, n. 1, p. 62-68, 2013. Disponível em: < http://www.sciencedirect.com/science/article/pii/S0378429013000269> doi: < 10.1016/j.fcr.2013.01.010>

AKHTAR, M.; KHAN, M. Z.; AHMAD, S.; AKHTAR, M. Response of Wheat to Different $\mathrm{N}, \mathrm{P}$ and $\mathrm{K}$ Rates of Applied Fertilizers under Rain fed Conditions of Pakistan. Asian Journal of Plant Sciences, v. 1, n. 1, p. 337-339, 2002.Disponível em: <http://198.170.104.138/ajps/2002/337-339.pdf >. doi: 10.3923/ajps.2002.337.339

SILVA, F. A. S. E. \& AZEVEDO, C. A. V. Principal Components Analysis in the Software Assistat-Statistical Attendance. In: WORLD CONGRESS ON COMPUTERS IN AGRICULTURE, 7, Reno-NV-USA: American Society of Agricultural and Biological Engineers, 2015. Disponível em: < http://www.assistat.com/indexp.html>

BAHMANYAR, M.A.; RANJBAR, G. A. The Role of Potassium in Improving Growth Indices and Increasing Amount of Grain Nutrient Elements of Wheat Cultivars. Journal of Applied Sciences, v. 8, n. 1, p. 1280-1285, 2008. Disponível em: $<$ http://www.scialert.net/fulltext/index.php?doi=jas.2008.1280.1285\&org=11>. Doi: $<0.3923 /$ jas.2008.1280.1285>

BAI, Y.; WANG, L., LU, Y.; YANG, L.; ZHOU, L.; NI, L.; CHENG, M. Effects of long-term full straw return on yield and potassium response in wheat-maize rotation. Journal of Integrative Agriculture, v.14, n.12, p. 2467-2476, 2015. Disponível em: < http://www.sciencedirect.com/science/article/pii/S2095311915612163> doi: $<10.1016 /$ S2095-3119(15)61216-3>

BRUNETTO, G.; GATIBONI, L. C.; SANTOS, D. R.; SAGGIN, A.;KAMINSKI, J. Nível crítico e resposta das culturas ao potássio em um Argissolo sob sistema plantio direto. Revista Brasileira Ciência do Solo, Viçosa, v. 29, n. 4, p. 565-571, 2005. Disponível

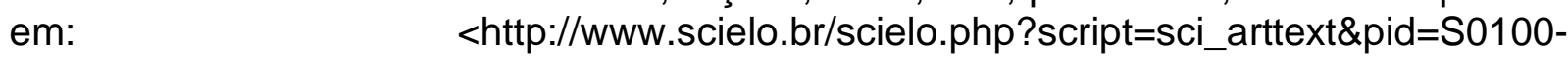
06832005000400009\&lng=en\&nrm=iso $>$. doi: $<10.1590 /$ S0100-06832005000400009>

CARMONA, F. C.; ANGHINONI, I.; MEURER, E. J. ; HOLZSCHUH, M.J. \& FRAGA, T.I. Estabelecimento do arroz irrigado e absorção de cátions em função do manejo da adubação potássica e do nível de salinidade do solo. Revista Brasileira de Ciência do Solo, Viçosa, MG, v. 33, n. 1, p. 371-383, 2009. Disponível em: <http://hdl.handle.net/10183/81190>. doi: < 0.1590/S0100-06832009000200015>

CECILIO FILHO, A. B.; GRANGEIRO, L. C.. Produtividade da cultura da melancia em função de fontes e doses de potássio. Ciência e Agrotecnollogia, Lavras, v. 28, n. 3, p. 561-569, $2004 \quad$ Disponível em: 
$<$ http://www.scielo.br/scielo.php?script=sci_arttext\&pid=S1413-

70542004000300011\&lng=en\&nrm=iso $>$. doi: $<10.1590 / S 1413-70542004000300011>$

COELHO, A. M.; YAMADA, T.; ROBERTS, T.L. Potássio na agricultura brasileira: O potássio na cultura do milho. Piracicaba, Instituto da Potassa e Fosfato, p.612-658, p. 613-658, 2005.

CONAB - COMPANHIA NACIONAL DE ABASTECIMENTO. Acompanhamento da safra brasileira de grãos. Brasília: CONAB, v. 1. , 2014. Disponível em: < http://www.conab.gov.br/OlalaCMS/uploads/arquivos/14_09_10_18_03_00_perspectiva s_2014-15.pdf>

DORÉ, T.; MAKOWSKI, D.; MALÉZIEUX, E.; MUNIER-JOLAIN, N.; TCHAMITCHIAN, M., \& TITTONELL, P. Facing up to the paradigm of ecological intesification in agronomy: revisiting methods, concepts, and know-ledge. European Journal of Agronomy, v. 34, n. $4, \quad$ p. 197-210, $2011 . \quad$ Disponível em: < http://www.sciencedirect.com/science/article/pii/S1161030111000220> doi:10.1016/j.eja.2011.02.006.

EL-TILIB, M. A.; ELNASIKH, M. H.; ELAMIN, E. A. Phosphorus and potassium fertilization effects on grow that tributes and yield do two sugar cane varieties grown on three soil series. Journal of Plant Nutrition, New York, v. 27, n. 4, p. 663-699, 2004. Disponível em: <http://www.docsdrive.com/pdfs/ansinet/jas/2007/2345-2350.pdf>. doi: $<1812-5654>$

Empresa Brasileira De Pesquisa Agropecuária (Embrapa). Centro Nacional de Pesquisa de Solos. Sistema brasileiro de classificação de solos. 3. ed. Rio de Janeiro: Embrapa, 2013.

Empresa Brasileira De Pesquisa Agropecuária (Embrapa). Centro Nacional de Pesquisa de Trigo. Informações técnicas para trigo e triticale - safra 2015 / VIII Reunião da Comissão Brasileira de Pesquisa de Trigo e Triticale. Brasília: Embrapa, 2014.

FAQUIN, V.; HOFFMANN, C.R.; EVANGELISTA, A.R. \& GUEDES, G.A. O potássio e o enxofre no crescimento da braquiária e do colonião em amostras de um Latossolo da região noroeste do Paraná. Revista Brasileira de Ciência do Solo, Campinas, v.19, n.1, p.87-94, $1995 . \quad$ Disponível em: $<$ http://www.scielo.br/scielo.php?script=sci_nlinks\&ref=000097\&pid=S01000683200300 040000800008\&lng=en>.

FOLONI, J.S.S.; ECHER, F.R.; CRESTE, J.E.; VILASBOAS, G.A. Ureia e nitrato de amônio via pulverização foliar no trigo. Cultura Agronômica, v.18, p.83-94, 2009. Disponível em: <http://www.scielo.br/scielo.php?script=sci_nlinks\&ref=000095\&pid=S0006$8705201000040002400009 \&$ lng $=$ pt>. doi: 
HECKMANN, J.R.; KAMPRATH, E.J. Potassium accumulatio and corn yield related to potassium fertilizer rate and placement. Soil Science Societyof American Journal, Madison, v.56, n.1, p.141-148, 1992. Disponível em: <https://dl.sciencesocieties.org/publications/sssaj/abstracts/56/1/SS0560010141>. doi: < 10.2136/sssaj1992.03615995005600010022x>

HOCHMAN, Z.; CARBERRY, P.S.; ROBERTSON, M.J; GAYDON, D.S.; BELL, L.W.; MCINTOSH, P.C. Prospects for ecological intensification of Australian agriculture. European Journal Agronomic, v. 44, n. 1, p. 109-123, 2013. Disponível em:< http://www.sciencedirect.com/science/article/pii/S1161030111001195> < doi: < 10.1016/j.eja.2011.11.003>

KAUTZ, T.; AMELUNG, W.; EWERT, F.; GAISER, T.; HORN, R.; JAHN, R.; JAVAUX, $M$. et al. Nutrient acquisition from arable sub soils in temperate climates: a review. Soil Biology \& Biochemistry, v. 57, p. 1003-1022, 2013. Disponível em:< http://www.sciencedirect.com/science/article/pii/S1161030111001195> < < 10.1016/j.eja.2011.11.003>

LIU, H. J.; ZHANG, J. C.; CHEN, L. G., XUE, X. H. Effects of strawre turning on annual overland runoff NPK loss in farmland. Ecology and Environmental Sciences, v. 21, p. 1031-1036, 2012. Disponível em: < https://www.elsevier.com/physicalsciences/environmental-science/environmental-science-and-ecology-journals>

MALAVOLTA, E. et al. Manual de nutrição de plantas. São Paulo: Agronômica Ceres, p. $638,2006$.

MU, P.; ZHANG, E. H.; WANG, H. N.; FANG, Y. F. Effects of continuous straw return to soil on maize growth and soil chemical and physical characteristics. Chinese Journal of Eco-Agriculture, v. 20, p. 291-296, 2012. Disponível em: < https://www.researchgate.net/publication/291009235_Effects_of_continuous_straw_retu rn_to_soil_on_maize_growth_and_soil_chemical_and_physical_characteristics> doi: < 10.3724/SP.J.1011.2012.00291>

PAVINATO, P.S. et al. Nitrogênio e potássio em milho irrigado: análise técnica e econômica da fertilização. Ciência Rural, v.38, n.2, p.358-364, 2008. Disponível em: <http://dx.doi.org/10.1590/S0103-84782008000200010. doi:10.1590/S0103$84782008000200010>$.

SCANLANA, C. A.; HUTHC, N.I.; BELLD, R. W. Simulating wheat growth response to potassium availability under field conditions with sandy soils. I. Model development. Field Crops Research, v. 178, n. 1, p. 109-124, 2015. Disponível em:< http://www.sciencedirect.com/science/article/pii/S0378429015001100> doi: < 10.1016/j.fcr.2015.03.019>

SIMILI, F. F.; REIS, R. A.; FURLAN, B. N. ; PAZ, C. C. P.; LIMA, M. L. P.; BELLINGIERI, P. A. Resposta do híbrido de sorgo-sudão à adubação nitrogenada e 
potássica: composição química e digestibilidade in vitro da matéria orgânica. Ciência agra tecnológica, Lavras, v. 32, n. 2, p. 474-480, mar./abr., 2008. Disponível em: < http://www.scielo.br/scielo.php?script=sci_arttext\&pid=S1413-70542008000200020> doi: < 10.1590/S1413-70542008000200020>

SUN, L. M.; LI, C. J. ; HE, P.; LIU, M. C.; HU, J. H. Effects of long term K application and straw returning on crop yield and soil $\mathrm{K}$ status in fluvo-aquic soil of Hebei Province. Plant Nutrition and Fertilizer Science, v. 18, p. 1096-1102, 2012. Disponível: < https://www.researchgate.net/publication/238383088_Effect_of_LongTerm_Application_of_K_Fertilizer_and_Wheat_Straw_to_Soil_on_Crop_Yield_and_Soil _K_Under_Different_Planting_Systems $>$ doi:< 10.1016/S1671-2927(07)60035-2>

UENO, R.K. et al. Dinâmica dos nutrientes do solo em áreas destinadas à produção de milho para forragem. Revista Brasileira de Tecnologia Aplicada nas Ciências Agrárias, v.4, n.1, p.182- 203, 2011. Disponível em: <http://revistas.unicentro.br/index.php/repaa/article/view/1427/1485>. doi: < 10.5777/PAeT.V4.N1.11>

XIE, J. G.; HOU, Y. P.; YIN, C. X. KONG, L. L.; QIN, Y. B.; LI, Q.; WANG, L. C. Effect of potassium application and straw returning on spring maize yield, nutrient absorption and soil potassium balance. Journal of Plant Nutrition and Fertilizer, v. 1, n. 1, p. 11101118, 2014. Disponível:<http://www.plantnutrifert.org/EN/abstract/abstract3384.shtml> doi:<10.11674/zwyf.2014.0507>

YANG, X. L.; LU, Y. L.; TONG, Y. A.; LIN, W.; LIANG, T. Effects of long-term N application and straw returning on $\mathrm{N}$ budget under wheat-maize rotation system. Plant Nutrition and Fertilizer Science, v. 19, p. 65-73, 2013. Disponível em: < http://www.plantnutrifert.org/EN/abstract/abstract3023.shtml> < 10.11674 /zwyf.2013.0108>

YU, C. C.; LIU, Y. G.; LIN, Q. Effects of depth of straw on sucrose content and yield of wheat. Chinese Agricultural Science Bulltin, v. 30, n. 1, p. 11-14, 2014.

VIANA, E. M. \& KIEHL, J. C. Doses de nitrogênio e potássio no crescimento do trigo. Bragantia [online]. v.69, n.4, p.975-982, 2010 http://dx.doi.org/10.1590/S000687052010000400024. 